\title{
Marangoni convection: velocity measurements using PTV method around a single vapor bubble
}

\author{
V. Carvalho ${ }^{a}$, M. Barthes, V. Lepiller and Y. Bailly \\ Institut FEMTO-ST, UMR CNRS 6174, dpt ENERGIE, 2 avenue Jean Moulin, 90000 Belfort Cedex, France
}

Received 17 June 2013, Accepted 16 March 2014

\begin{abstract}
An experimental investigation of the Marangoni convection around a single vapor bubble of FC72 on a downward-facing heated surface was reported. The boiling cell used for this study was equipped with an optical measurement system which was dedicated to the Particle Tracking Velocimetry (PTV) method. This method allowed us to obtain the velocity fields in the liquid around the vapor bubble. From the velocity fields obtained, we verified the presence of Marangoni convection rolls in the vicinity of the liquid-vapor interface. Lastly, the influence of levels of subcooling on the velocity of convective rolls related to the Marangoni effect was investigated.
\end{abstract}

Key words: Marangoni convection / vapor bubble / Particle Tracking Velocimetry (PTV) / FC-72

Résumé - Mesures de la vitesse autour d'une bulle unique de vapeur par PTV. Ces travaux portent sur la caractérisation hydrodynamique de la convection de Marangoni autour d'une bulle de vapeur unique de FC-72. Une cellule d'ébullition est utilisée pour générer la bulle unique de vapeur dans le liquide sous refroidi. Un système de mesure optique de PTV (Particle Tracking Velocimetry) est monté sur la cellule et permet d'obtenir les champs de vitesse au niveau de l'interface liquide-vapeur. Ainsi l'observation de la convection de Marangoni sous forme de rouleaux a été possible. L'influence du niveau de sous refroidissement du liquide sur la vitesse de ces rouleaux convectifs a été mise en évidence dans cette étude.

Mots clés : convection de Marangoni / bulle de vapeur / méthode PTV / FC-72

\section{Introduction}

When there is a surface tension gradient along an interface between two immiscible fluids, we may see a fluid movement along this interface called the Marangoni convection. Marangoni, an Italian scientist, was the first to describe this phenomenon of fluid motion in his works from 1865 [1]. The surface tension, $\sigma$, is function of the temperature $T$, the concentration $c$, and of the electrical potential $E$. The variation of the surface tension versus $s$, the curvilinear coordinate in the direction of the surface tension gradient, is given by the following equation:

$$
\frac{d \sigma}{d s}=\frac{\partial \sigma}{\partial T} \frac{\partial T}{\partial s}+\frac{\partial \sigma}{\partial c} \frac{\partial c}{\partial s}+\frac{\partial \sigma}{\partial E} \frac{\partial E}{\partial s}
$$

When the temperature is the only parameter that has an influence on the surface tension variation, Marangoni convection is called thermocapillary convection. The interface that separates the two fluids, may take different

\footnotetext{
${ }^{a}$ Corresponding author: victor. carvalho@femto-st.fr
}

forms like planar or bubble. Here we focus on a bubble shape interface.

Many studies were carried out on Marangoni convection in the case of an air bubble injected in a liquid layer (i.e. without phase change) [2-4]. Fewer studies were conducted in the case of a vapor bubble, i.e. with liquid-vapor phase change $[5,6]$. For both operating conditions (air or vapor bubble), most of these studies focused on the thermal aspects rather than the flow dynamics. For instance, Wozniak et al. [7] showed the influence of the liquid's bulk temperature (silicone oil) on the velocity of convective rolls around an air bubble which was injected into a silicone oil layer submitted to a vertical thermal gradient. They deduced from the traking of Liquid Crystal tracer particles the velocity of convective rolls.

The purpose of this study is the Marangoni convection in the case of a vapor bubble that grows under a heated wall. More precisely we focused on the influence of the level of subcooling on the dynamics of the convective flow around a single vapor bubble of FC-72. The 


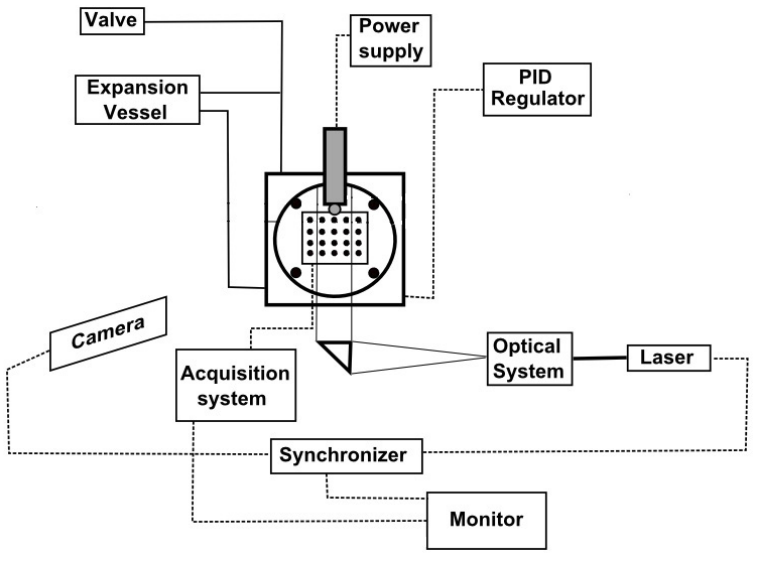

(a)

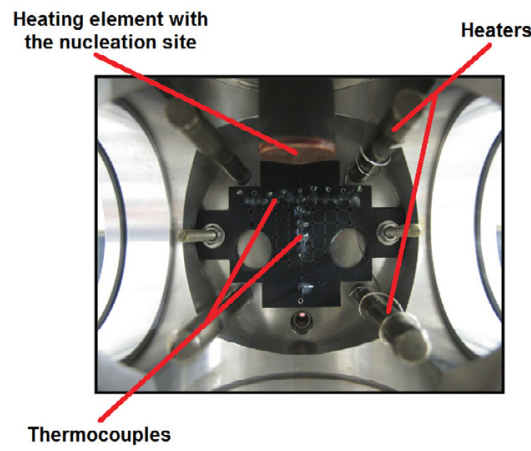

(b)

Fig. 1. (a) Diagram of the experimental bench and (b) a picture of the inside of the boiling cell.
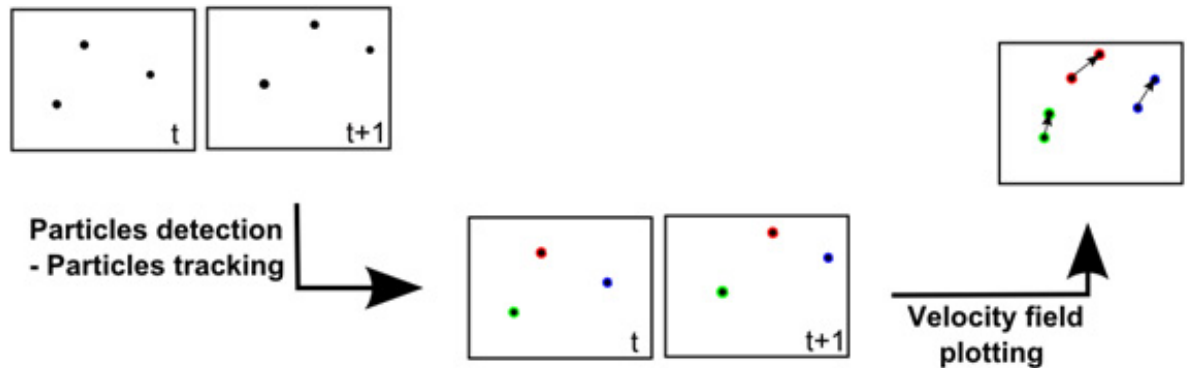

Fig. 2. Illustration of the principle of the PTV method.

Particle Tracking Velocimetry (PTV) method was used to obtain velocity fields in the vicinity of the liquid-vapor interface and was already successfully tested in [8].

In the next section, the experimental bench is described in two parts. The first past discusses the generation of the vapor bubble and the second explains the method for measuring the velocity of the Marangoni convection. Then the results obtained are presented and discussed in Section 3.

\section{Experimental rig}

Figure 1a shows a schematic of the experimental bench used for this study. It was composed of the boiling cell, set of equipment necessary for the PTV method operating controls, and data acquisition system.

\subsection{Boiling cell}

The boiling cell (cf. Figs. 1a and 1b) was a cube of stainless steel with an internal volume of $720 \mathrm{~cm}^{3}$ (external dimension: $\left.110 \times 110 \times 120 \mathrm{~cm}^{3}\right)$. The top side of the cell was used to support the heating element. One of the sides was used to support the instrumentation (heating of the liquid bath, temperature sensors). And the last four sides were composed of glass windows that allowed the optical measurements. The cell was filled with non degassed Fluorinert FC-72. We used an expansion vessel with a variable volume to maintain the cell at atmospheric pressure. To observe the thermocapillary convection, a temperature gradient must be present alongside the bubble's interface. Thus we worked with a subcooled liquid (with a temperature below the saturation temperature). The heating element was then the hot spot, and the subcooled liquid the cold spot. Four heaters were used to maintain the fluid at a required temperature. The fluid temperatures were measured by thermocouples and fixed using a PID controller. The temperature sensors were K type thermocouples manufactured and calibrated in our laboratory. The heating element was a downward facing one (to reach larger bubble's size and growth periods). It was composed of an electrical resistance and a polished copper disc. The artificial nucleation site was located in the center of the disc. It had a conical shape with a diameter of $100 \mu \mathrm{m}$ and an apex angle of $45^{\circ}$.

\subsection{PTV system}

The principle of the PTV (Particle Tracking Velocimetry) method consists in seeding a flow with reflecting particles. A plane of the liquid is illuminated by two light pulses separated with a known time interval. A camera placed perpendicular to light sheet records two images corresponding to each pulse of light. An image processing is performed on the images and presents the spatial displacement of the liquid (see Fig. 2). Knowing the spatial 


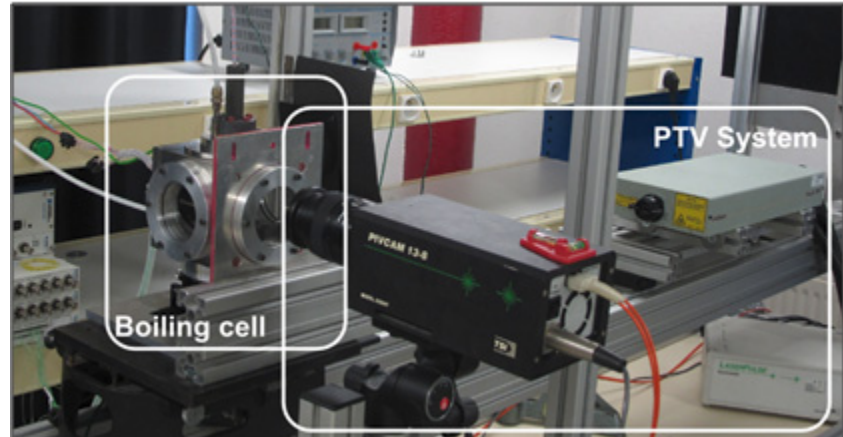

Fig. 3. Picture of PTV system on the experimental setup.

displacement and the time interval, velocity vector fields are obtained.

In this study, we used the commercial software Insight (TSI) for the image processing. A first algorithm consists in the identification of each particle location in the initial picture. Then a tracking algorithm looks for the identified particle from the picture $t$ to the picture $t+1$. Finally, a bicubic interpolation algorithm determines the velocity fields.

The system of velocimetry used in this study is illustrated in Figure 3. A suitable optical system provided obtains a light sheet from a pulsed Nd:YAG laser (with a wavelength of $532 \mathrm{~nm}$ ). The seeding particles were hollow glass beads coated with silver. Images were recorded in 12 bits by a CCD camera (TSI PIVCAM 13-8) with a resolution of $1280 \times 1024$ pixels. The camera lens used this study was a Nikon AF micro nikkor, $60 \mathrm{~mm}$ 1:2.8 D. A synchronizer was used for the data of laser pulses and image acquisition simultaneously.

\section{Results-discussion}

The only parameter that varied in this study was a thermal one: the level of subcooling $\Delta T_{\text {sub }}$. It corresponds to the temperature difference between the liquid bulk and the saturation. The temperature of the liquid bulk used was obtained by an average of values delivered by the thermocouples in the liquid bath (cf. Fig. 1b).

An atmospheric pressure was maintained and the associated saturation temperature for the FC-72 was $329.8 \mathrm{~K}$ [8]. Three levels of subcooling were investigated: $16.9 \mathrm{~K}, 18.8 \mathrm{~K}$ and $20.8 \mathrm{~K}$. The heating power for the nucleation surface was set at $1.62 \mathrm{~W}$. These parameters were selected based on a previous study [9] that showed the presence of Marangoni convection around a vapor bubble in similar operating conditions.

Figure 4 shows an example of velocity field obtained for a level of subcooling equal to $18.8 \mathrm{~K}$. We can see in this figure the vapor bubble and, on its left side, a convective roll. The liquid near the interface was driven from the base (hot spot located near the heating wall) to the top (cold spot, in the subcooled liquid) of the bubble. The liquid displacement was thus due to the surface tension gradient

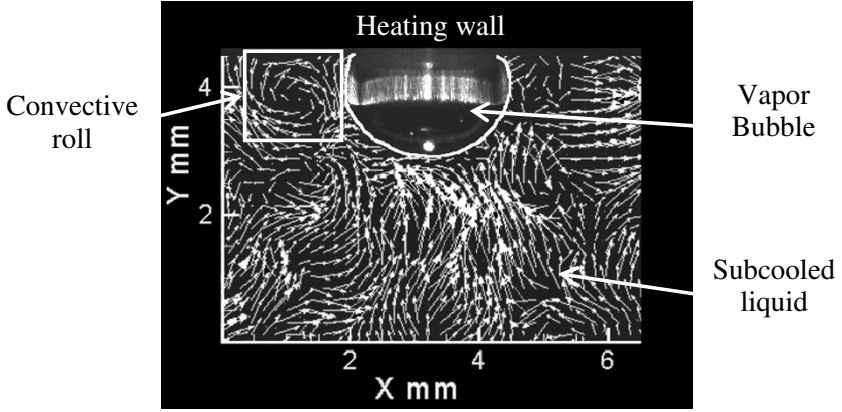

Fig. 4. Velocity fields obtained for a level of subcooling of $18.8 \mathrm{~K}$ (heating power: $1.62 \mathrm{~W}$ ).

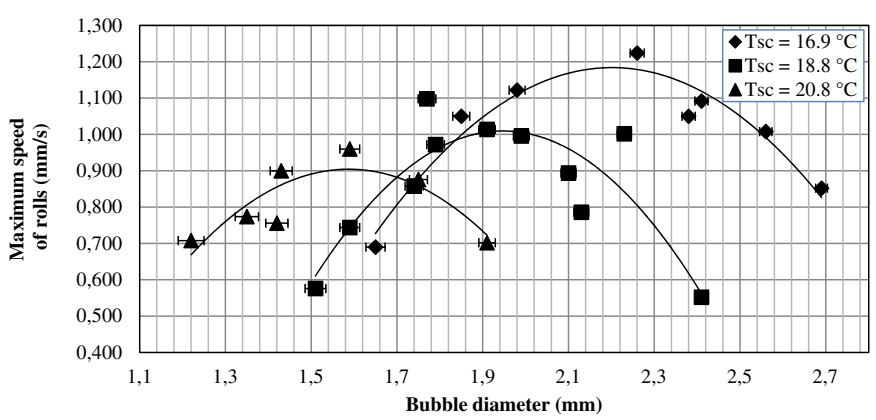

Fig. 5. Maximum velocity of rolls versus a bubble diameter for the different levels of subcooling $\Delta T_{\text {sub }}$.

that existed along the liquid-vapor interface. This phenomenon is characteristic of Marangoni convection.

One can also see on Figure 4 that the roll is not symmetrical: it is not visible on both sides of the vapor bubble. On this picture, operating conditions (thermal and geometrical parameters) corresponded to the observation of the oscillatory state. Indeed, the Marangoni convection is a three dimensional phenomenon. Depending on various parameters (such as thermal or geometrical), there is a transition from steady state to an oscillatory mode [10]. Reynard et al. [11] used tracer particles to observe those modes around an air bubble injected in a silicone oil layer. Concerning the vapor bubble, those authors used the shadowgraphy method to emphasize the presence of oscillatory mode. For small bubbles and/or lower temperature difference between the heated wall and the liquid, the steady state corresponded to a symmetrical tore existing around the bubble. Then for larger bubbles and/or higher temperature gradients, 3D oscillations were observed. They corresponded to a distortion of the roll into several patterns: the roll structure was composed of outward and inward extrema which were periodically space and time dependent.

From the velocity vector fields, maximum velocities were determined for convective rolls and found to be between 0.5 to $1.5 \mathrm{~mm} . \mathrm{s}^{-1}$. The order of magnitude of these velocities was found to be identical to the one measured around an air bubble injected into an alcohol and a glycerol liquid layer [12]. Figure 5 shows maximum velocities versus the bubble diameter (here corresponding to 
the major axis of the bubble). First, during the bubble growth (i.e. bubble's diameter increase), velocities increased. Then, the velocity decreased after the bubble reached a diameter turned the "critical diameter": $1.58 \mathrm{~mm}, 1.94 \mathrm{~mm}$ and $2.20 \mathrm{~mm}$ for levels of subcooling of $20.8,18.8$ and $16.9 \mathrm{~K}$ respectively. Based on visualisations, this critical diameter seemed to correspond to the transition from the stationary (axial symmetry) to the oscillatory mode. The maximum velocities corresponding to these critical diameters were equal to $0.96,1.09$ and $1.22 \mathrm{~mm} . \mathrm{s}^{-1}$. Thus, we observed an increase in the maximum of velocity when the level of subcooling decreased.

The level of subcooling was directly related to the temperature of the liquid bulk and to the vertical thermal gradient. An increase of the liquid bulk temperature also implied the decrease of the FC-72 viscosity. Moreover, when the level of subcooling decreased, the onset of the oscillatory state occurred for larger bubbles [11]. Combining these effects, the liquid motion should be eased (by the viscosity decrease) and larger stationary rolls should be observed (larger bubble size). This could explain the fact that the critical velocity increased for smaller levels of subcooling and larger bubble diameters. The PTV can only deliver $2 \mathrm{D}$ information whereas the oscillatory state is $3 \mathrm{D}$. To verify our hypothesis, future studies will be carried out using a 3D optical method: the Rainbow Volumic Velocimetry RVV [13].

\section{Conclusion}

In this study, we used the Particle Tracking Velocimetry (PTV) method to characterize the Marangoni convection around a single vapor bubble of FC-72. The vapor bubble was generated on a downward facing heating element in subcooled FC-72. The PTV method allowed us to obtain the velocity fields of the liquid near the liquid-vapor interface for various levels of subcooling. From these velocity fields we noted the maximum of velocity in convective rolls related to the Marangoni effect. This maximum of velocity increased when the level of subcooling decreased. For levels of subcooling equal to 20.8, 18.8 and $16.9 \mathrm{~K}$, maximum velocities were equal to $0.96,1.09$ and $1.22 \mathrm{~mm} . \mathrm{s}^{-1}$. Marangoni convection is a three-dimensional dynamic phenomenon with different modes (depending on parameters such as bubble size and liquid subcooling). To investigate and characterize the Marangoni convection in the three spatial dimensions, another optical method will be used: the Rainbow Volumic Velocimetry (RVV) method [13].

\section{References}

[1] L.E. Scriven, C.V. Sternling, The Marangoni Effects, Nature 187 (1960) 186-188

[2] C.H. Chun, D. Raake, G. Hansmann, Oscillating convection modes in the surroundings of an air bubble under a horizontal heated wall, Exp. Fluids 11 (1991) 359-367

[3] G. Wozniak, Optical whole-field methods for thermoconvective flow analysis in microgravity, Meas. Sci. Technol. 10 (1999) 878

[4] J. Straub, Origin and Effect of Thermocapillary Convection in Subcooled Boiling, Ann. N. Y. Acad. Sci. 974 (2002) 348-363

[5] Y.S. Kao, D.B.R. Kenning, Thermo capillary flow near a hemispherical bubble on a heated wall, J. Fluid Mech. 53 (1972) 715-735

[6] M. Barthès, C. Reynard, R. Santini, L. Tadrist, Détermination des caractéristiques géométriques de la croissance d'une bulle de vapeur et des transferts de chaleur associés: influence des incondensables sur le déclenchement d'instabilités convectives, Mecanique et Industries 6 (2010) 257

[7] K. Wozniak, G. Wozniak, T. Rösgen, Particle-imagevelocimetry applied to thermocapillary convection, Exp. Fluids 10 (1990) 12-16

[8] Aldrich Chemical Company Inc., 1990 Aldrich Chemical Company Inc. Catalog Handbook of Fine Chemicals, Aldrich Chemical Company, Inc., Milwaukee WI, 1990, 1

[9] V. Carvalho, M. Barthès, V. Lepiller, Y. Bailly, Caractérisation de la convection thermocapillaire autour d'une bulle de vapeur nucléée par la méthode PIV 2D, Congrès Français de Visualisation et de Traitement d'Images en Mécanique des Fluides, 201

[10] M. Kassemi, N. Rashidnia, Steady and oscillatory thermocapillary convection generated by a bubble, Phys. Fluids 12 (2000) 3133-3146

[11] C. Reynard, M. Barthès, R. Santini, L. Tadrist, Experimental study of the onset of the 3D oscillatory thermocapillary convection around a single air or vapor bubble: Influence on heat transfer, Exp. Therm. Fluid Sci. 29 (2005) 783-793

[12] V.I. Baranenko, L.A. Chichkan, Thermocapillary Convection in the Boiling of Various Fluids, Heat Transfer, Soviet Res. 12 (1980) 40-44

[13] J. Prenel, Y. Bailly, Recent evolutions of imagery in fluid mechanics: From standard tomographic visualization to $3 \mathrm{D}$ volumic velocimetry, Optics and Lasers in Engineering, Opt. Meth. Heat Transfer Fluid Flow 44 (2006) 321-334 